\title{
Hybrid DC circuit breaker with coupled inductor for automatic current commutation
}

DOI:

10.1016/j.jjepes.2020.106004

\section{Document Version}

Accepted author manuscript

Link to publication record in Manchester Research Explorer

\section{Citation for published version (APA):}

Pei, X., Smith, A. C., Cwikowski, O., \& Barnes, M. (2020). Hybrid DC circuit breaker with coupled inductor for automatic current commutation. International Journal of Electrical Power \& Energy Systems, 120. https://doi.org/10.1016/j.ijepes.2020.106004

\section{Published in:}

International Journal of Electrical Power \& Energy Systems

\section{Citing this paper}

Please note that where the full-text provided on Manchester Research Explorer is the Author Accepted Manuscript or Proof version this may differ from the final Published version. If citing, it is advised that you check and use the publisher's definitive version.

\section{General rights}

Copyright and moral rights for the publications made accessible in the Research Explorer are retained by the authors and/or other copyright owners and it is a condition of accessing publications that users recognise and abide by the legal requirements associated with these rights.

\section{Takedown policy}

If you believe that this document breaches copyright please refer to the University of Manchester's Takedown Procedures [http://man.ac.uk/04Y6Bo] or contact uml.scholarlycommunications@manchester.ac.uk providing relevant details, so we can investigate your claim.

\section{OPEN ACCESS}




\title{
Hybrid DC circuit breaker with coupled inductor for automatic current commutation
}

\author{
Xiaoze Pei ${ }^{\mathrm{a}}$, Alexander C. Smith ${ }^{\mathrm{b}}$, Oliver Cwikowski ${ }^{\mathrm{c}}$, Mike Barnes ${ }^{\mathrm{b}}$ \\ ${ }^{a}$ Department of Electronic and Electrical Engineering, University of Bath, BA2 7AY, U. K. \\ ${ }^{\mathrm{b}}$ Power and Energy Division, School of Electrical and Electronic Engineering, The University of Manchester, M13 9PL, U. K. \\ ${ }^{\mathrm{c}}$ National Grid, National Grid House, Warwick Technology Park, Gallows Hill, Warwick, CV34 6DA, U. K.
}

\begin{abstract}
HVDC transmission systems using voltage source converters (VSC-HVDC) have been identified as an attractive solution for bulk power delivery over long distance. However if DC grids are to be built using this technology, fast DC circuit breakers are needed. This work proposes a new hybrid DC circuit breaker utilizing a series connected coupled inductor connected, which enables automatic current commutation from the mechanical switch to the semiconductor switch during a fault. The key advantage of the proposed DC circuit breaker is that the current in the mechanical switch automatically reduces to zero when a fault happens. This paper focuses on comparison of different mechanisms to commutate the current from the mechanical switch to the semiconductor switch and create a zero current for the mechanical switch. Three types of hybrid DC circuit breaker topologies including proactive hybrid DC circuit breaker, hybrid DC circuit breaker with commutation booster, and hybrid DC circuit breaker with coupled inductor for a $500 \mathrm{kV}$ HVDC system are simulated and compared using Matlab/Simulink. A prototype hybrid DC circuit breaker with coupled inductor is designed and built. The prototype is capable of interrupting 200 A direct current within $4 \mathrm{~ms}$. The automatic current commutation compensates for the fault detection and location time in the selective protection scheme, which provides faster fault current interruption.
\end{abstract}

Keywords - Coupled inductor, current commutation, hybrid DC circuit breaker, mechanical switch, semiconductor switch.

\section{Introduction}

DC transmission and distribution networks can provide substantial benefits over traditional three-phase alternating current (AC) networks in terms of system efficiency and control flexibility [1]. Voltage-sourced converter high voltage direct current (VSC-HVDC) transmission systems have demonstrated their potential in bulk power delivery over long distance [2-4]. Multi-terminal DC (MTDC) networks and meshed DC grids have been widely suggested as a cost effective means of integrating offshore renewable energy [3-5] and the first meshed HVDC grid is being built in China [6, 7]. Medium voltage direct current (MVDC) distribution networks have also been proposed for transportation electrification and power distribution [8-11].

One of the key barriers for the development of MTDC networks is managing faults directly on the DC networks. Current breaking in a DC system is significantly more challenging than in an AC system because: firstly, there are no

Email address: x.pei@bath.ac.uk. natural zero-crossings of the current to enable interruption of the fault; secondly, the rate of rise of the fault current is much higher in DC networks [12-15]. A number of DC circuit breaker topologies have been proposed [16]. Mechanical circuit breakers have low operating losses due to very low contact resistance. However at the moment they are too slow for DC networks [17, 18]. The performance of mechanical circuit breakers is improving and making good progress for HVDC applications [19, 20]. Semiconductor circuit breakers can interrupt fault current within $100 \mu$ s but the on-state losses are high during normal operation [21,22]. A hybrid DC circuit breaker, which combines the advantages of the mechanical switch in the normally conducting path with the semiconductor switch the breaking path, is an attractive option for practical HVDC circuit breakers. Industrial companies are making good progress in developing full scale commercial devices [7], [23-31]. These hybrid DC circuit breakers require a large and bulky DC reactor to limit the rate of rise of the fault current $[13,29,32,33]$. This reactor causes conduction losses and also may affect stability of the DC grid, which poses control challenges [34]. The value of the DC reactor is determined by the HVDC system voltage, the semiconductor switch maximum interrupting current, the fault current detection and interruption time. The value of the DC reactor can be reduced if the fault current detection and interruption time is reduced.

This paper focuses on the investigation of the commutation of large fault currents from the mechanical switch to the semiconductor switch. The current commutation by the arc voltage of the mechanical switch is slow and causes erosion of the contacts [35]. Passive LC resonance circuits and active injection resonance circuits are commonly used current commutation methods for hybrid DC circuit breakers [27, 36]. A molten bridge method has also been considered for the current commutation [37]. The current commutation process in a medium voltage hybrid DC circuit breaker is analyzed in [38]. A hybrid DC circuit breaker with commutation booster topology has been proposed where a coupled inductor is connected into the primary and secondary parallel branches [39-42]. The coupled inductor is used to commutate the current from the mechanical switch to the semiconductor switch during the fault. However, this topology has significant design constraints: the ratio between the self-inductance of the primary winding and the secondary winding and also the mutual coupling between them has to satisfy specific 
requirements to enable to the current commutation [40]. A current commutation circuit consisting of a coupled inductor, a charged capacitor and a thyristor has also been investigated $[35,43]$.

In this paper a hybrid DC circuit breaker with a coupled inductor connected in series is proposed and investigated. The novelty of this circuit breaker is primarily the use of the coupled inductor to force the fault current to transfer automatically from the mechanical switch into the semiconductor switch. Also, the design of the primary and secondary windings of the coupled inductor is less constrained. The benefits of the proposed DC breaker include: firstly, the automatic current commutation creates a current zero for the mechanical switch; secondly, the semiconductor switch can be switched off once the fault is detected and located.

The structure of the paper is organized as follows. Section 2 introduces the topology and operating principle of three type of hybrid DC circuit breakers including the proactive hybrid DC circuit breaker, the hybrid DC circuit breaker with commutation booster, and the hybrid DC circuit breaker with coupled inductor. Section 3 focuses on design and modeling of $500 \mathrm{kV}$ hybrid DC circuit breaker using these three hybrid DC circuit breaker topologies. Section 4 presents the design and experimental testing of a low voltage coupled inductor hybrid DC circuit breaker technology demonstrator.

\section{Hybrid DC circuit breaker topology and operating principle}

\subsection{Proactive hybrid DC circuit breaker}

The proactive hybrid circuit breaker presented in $[23,24]$ is shown in Fig. 1. The hybrid circuit breaker consists a mechanical switch, a load commutation switch (LCS) and a main DC breaker. The main DC breaker comprises a large number of semiconductor switches connected in parallel groups with the varistors. The load commutation switch is used to commutate the current form the mechanical switch to the main DC breaker when a fault happens. The load commutation switch is a few semiconductor switches, which produces significantly lower on-state losses than the main DC breaker.

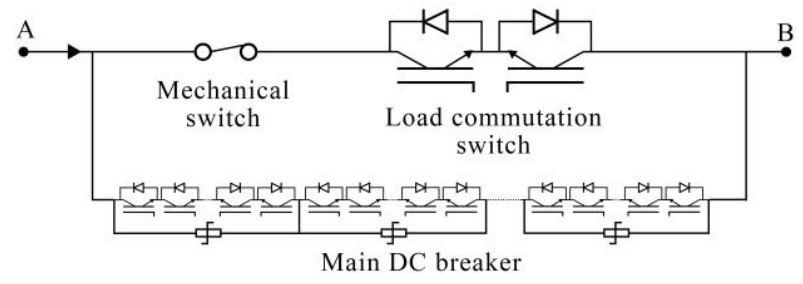

Fig. 1. Hybrid DC circuit breaker schematic diagram [23].

During normal operation, the mechanical switch is closed and the load commutation switch is on, the current flows through the mechanical switch. When a fault is detected, the main DC breaker is turned on if it is not on before. The load commutation switch is then turned off, and its snubber circuit (not shown) charges and produces voltage to commutate the current from the mechanical switch into the main DC breaker. Once all the current flows through the main DC breaker, the mechanical switch is opened with effectively zero current. The main DC breaker is turned off once the mechanical switch is fully open and is able to withstand the transient recovery voltage. The energy absorbing varistor limits the voltage across the hybrid DC circuit breaker to a pre-determined maximum level and de-energizes the inductance in the system. The mechanical disconnector blocks the majority of the voltage across the hybrid DC circuit breaker, and so the load commutation switch only needs a low voltage rating. This hybrid circuit breaker allows a proactive commutation of the current into the main DC breaker to compensate for the time delay of the mechanical switch and since the mechanical switch opens at zero current, its operation can be very fast [23].

\subsection{Hybrid DC circuit breaker with commutation booster}

The commutation booster using coupled inductor connected in parallel branches was proposed and patented [39, 40]. Fig. 2 shows the schematic diagram of the hybrid DC circuit breaker with commutation booster. The inductively coupled inductor is introduced to aid commutation and is called the commutation booster. The hybrid DC circuit breaker comprises a parallel connected coupled inductor (shown in the dashed box), a mechanical switch, a semiconductor switch and a varistor. The mechanical switch, semiconductor switch and varistor contain one or more units connected in parallel and/or in series depending on the current and voltage ratings. $L_{l}$ and $L_{2}$ are the self-inductances of the primary and secondary windings of the coupled inductor and $M$ is the mutual inductance between them. The inductance in the primary branch has to be designed to be higher than the secondary branch inductance so that when the current increases, all the current flows into the secondary branch.

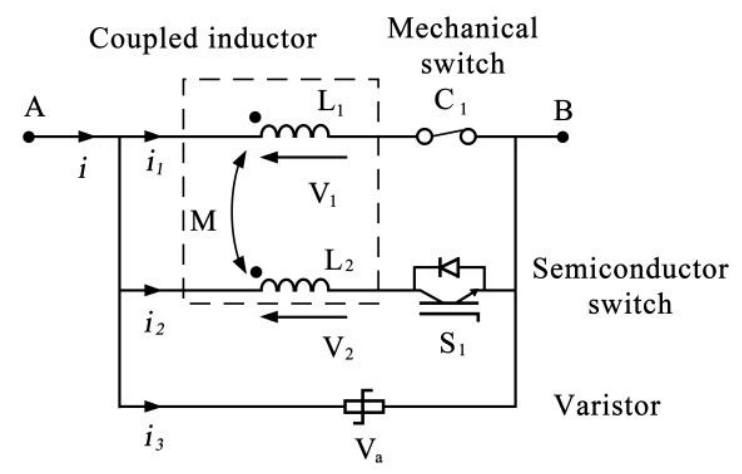

Fig. 2. Hybrid DC circuit breaker with commutation booster schematic diagram [36].

During normal operation, both the mechanical switch and the semiconductor switch are on. Almost all the current flows through the mechanical switch because it is low impedance path. The current during normal operation before the fault occurs is shown as follows:

$$
\begin{aligned}
& i_{1}=i \\
& i_{2}=0
\end{aligned}
$$

where $i$ is the instantaneous current in the system. $i_{1}$ is the current in the primary branch and $i_{2}$ is the current in the secondary branch.

Once a fault occurs, the fault current increases rapidly with 
a rate of rise, which can be expressed as:

$$
\frac{d i}{d t} \gg 0
$$

According to Kirchhoff's current law, the rate of rise of the fault current equals to the current change in the parallel branches:

$$
\frac{d i}{d t}=\frac{d i_{1}}{d t}+\frac{d i_{2}}{d t}
$$

The voltage of the primary winding $V_{1}$ and the secondary winding $V_{2}$ can be expressed as follows:

$$
\begin{aligned}
& V_{1}=L_{1} \frac{d i_{1}}{d t}+M \frac{d i_{2}}{d t} \\
& V_{2}=L_{2} \frac{d i_{2}}{d t}+M \frac{d i_{1}}{d t}
\end{aligned}
$$

The mutual inductance depends on the self-inductance of the primary winding and secondary winding, and coupling between them.

$$
M=k \sqrt{L_{1} L_{2}}
$$

$k$ is coupling coefficient of the coupled inductor. The coupling coefficient is related to mutual inductance and selfinductances in the following way.

$$
0 \leq k<1
$$

When a fault occurs, the mechanical switch and semiconductor switch are conducting, the voltage across the primary winding equals to the voltage across the secondary winding and the voltage drop on the semiconductor switch $V_{s}$ :

$$
V_{1}=V_{2}+V_{s}
$$

The rate of change of the current in the primary mechanical switch branch and secondary semiconductor switch branch can be obtained from equations 3 to 9 .

$$
\begin{gathered}
\frac{d i_{1}}{d t}=\frac{\left(L_{2}-M\right) \frac{d i}{d t}+V_{s}}{L_{1}+L_{2}-2 M} \\
\frac{d i_{2}}{d t} \approx \frac{\left(L_{1}-M\right) \frac{d i}{d t}-V_{s}}{L_{1}+L_{2}-2 M}
\end{gathered}
$$

The number of the semiconductor devices connected in series depends on the system voltage level. The voltage across the semiconductor switch is insignificant compared with voltage across the coupled inductor and can be ignored in an initial calculation. In this case, the voltage across the primary winding can be assumed to be similar to the secondary winding:

$$
V_{1} \approx V_{2}
$$

The rate of the current change in the primary and secondary branches with respect to the change of the total fault current can be expressed as follow:

$$
\begin{aligned}
& \frac{d i_{1}}{d t} \approx \frac{L_{2}-M}{L_{1}+L_{2}-2 M} \frac{d i}{d t} \\
& \frac{d i_{2}}{d t} \approx \frac{L_{1}-M}{L_{1}+L_{2}-2 M} \frac{d i}{d t}
\end{aligned}
$$

During a fault, the rate of change of the fault current $d i / d t$ is high. In order to commutate the current from the mechanical switch to the semiconductor switch, in which case $d i_{1} / d t$ is expected to be negative, it is clear from equation 13 that the mutual inductance has to be greater than the self-inductance of the secondary winding to enable the current commutation. In other words, the self-inductance of the primary winding has to be greater than the self-inductance of the secondary winding as mentioned in [40].

This current commutation creates a current zero-crossing in the mechanical switch which allows it to interrupt the current in a similar way to an AC breaker. The semiconductor can be turned off once the mechanical switch is able to withstand the system voltage. The varistor limits the voltage across the circuit breaker after the semiconductor is turned off.

\subsection{Hybrid DC circuit breaker with coupled inductor}

The schematic diagram of the DC circuit breaker with a series connected coupled inductor proposed in this paper is shown in Fig. 3. For simplicity, a unidirectional breaker only is shown. The coupled inductor primary winding is connected in series with three parallel conduction paths. The primary conduction path is the mechanical switch in series with the inductor secondary winding. There is a secondary conduction path comprising the semiconductor switch. The third conduction path comprises the varistor. In this hybrid DC circuit breaker configuration, the coupled inductor is arranged to transfer the current from the primary conduction path of the mechanical switch to the secondary conduction path of the semiconductor switch in response to an increasing current in the circuit. Once the primary branch current has been fully commutated, this produces a zero-crossing of the current to allow the mechanical switch to recover its voltage withstand capability.

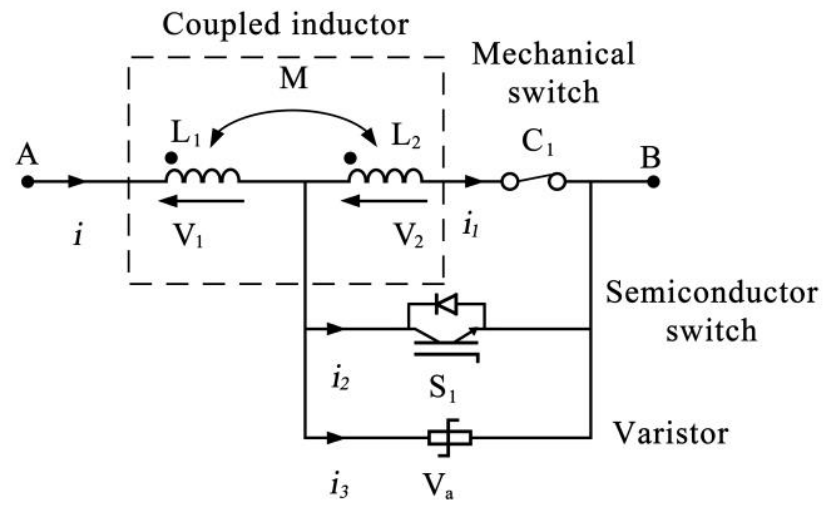

Fig. 3. Hybrid DC circuit breaker with coupled inductor schematic diagram.

During normal operation, both the mechanical switch and semiconductor switch are closed. The steady-state current flows through the mechanical switch branch as the low impedance path. When a fault occurs, the current in the primary winding $L_{l}$ increases quickly. An electromagnetic force (emf) is then induced across the secondary winding $\mathrm{L}_{2}$ through the mutual inductance $M$. When the semiconductor switch is in the on-state, this emf automatically forces the current to start to transfer from the mechanical switch to the semiconductor switch. The contacts of the mechanical switch can be separated when the current in it reduces to close to zero. The mechanical switch then starts to recover its voltage withstand level as the semiconductor switch conducts the fault current. The semiconductor switch is then turned off after the mechanical switch recovers its full voltage withstand level.

The circuit current flows through the primary mechanical 
switch during normal operation as shown in Fig. 3. The initial branch currents during normal operation and before the fault occurs is:

$$
\begin{aligned}
& i_{1}=i \\
& i_{2}=0
\end{aligned}
$$

The voltage across the secondary winding can be expressed as:

$$
V_{2}=L_{2} \frac{d i_{1}}{d t}+M \frac{d i}{d t}
$$

When a fault occurs, both the mechanical switch and the semiconductor switch are conducting. The voltage across the secondary winding must equal therefore the voltage drop across the semiconductor switch $V_{s}$. The rate of change of the current in the mechanical switch is therefore:

$$
\frac{d i_{1}}{d t}=-\frac{M \frac{d i}{d t}-V_{s}}{L_{2}}
$$

The rate of change of the current in the secondary branch is thus:

$$
\frac{d i_{2}}{d t}=\frac{\left(L_{2}+M\right) \frac{d i}{d t}+V_{s}}{L_{2}}
$$

If the voltage drop across the semiconductor switch is ignored, the rate of change of the branch currents are:

$$
\begin{aligned}
& \frac{d i_{1}}{d t} \approx-\frac{M}{L_{2}} \frac{d i}{d t} \\
& \frac{d i_{2}}{d t} \approx\left(1+\frac{M}{L_{2}}\right) \frac{d i}{d t}
\end{aligned}
$$

It is clear from equation 20 that the current commutation from the mechanical switch to the semiconductor switch depends on the mutual inductance of the coupled inductor and the rate of rise of the fault current. The current will naturally transfer from the mechanical switch branch to the semiconductor switch branch as long as the two windings are magnetically coupled together in such a direction noted in Fig. 3. Interestingly if an inductor with a high coefficient of coupling is considered, so that the inductance ratio in equation 20 is close to unity, the current in the mechanical switch reduces at the same rate as the rate of the rising fault current. The current transfer capability is clearly only dependent on the mutual inductance not the self-inductance ratio, allowing greater flexibility in the design of the system, for example, to design the self-inductances to limit the rate of fault current rise. This offers flexibility in the design of the coupled inductor and the two windings can be designed to be identical. This also simplifies the winding coupling design. For fast current commutation, the primary and secondary windings should be closely coupled (coupling coefficient close to unity) so that the mutual inductance between the windings is only slightly lower than the self-inductances. The biggest boost is however achieved for fast changes in current, the mechanical switch $C_{1}$ needs to be rated to allow the breaker to break normal (1pu) steady-state load current.

\section{Design and modelling of a $500 \mathrm{kV}$ hybrid DC circuit breaker}

\subsection{System parameters}

To compare the three topologies of hybrid DC circuit breakers, they have been designed and simulated based on the Zhangbei $500 \mathrm{kV}$ HVDC grid [7, 29]. The Zhangbei HVDC grid is a $\pm 500 \mathrm{kV} / 3000 \mathrm{MV}$ four terminal DC grid project. The capacity of the modular multi-level (MMC) converter station at Zhangbei and Beijing are both rated at $3000 \mathrm{MW}$. The rated operating current between Zhangbei and Beijing are $3 \mathrm{kA}$. The overcurrent threshold for the blocking MMC converter station between Zhangbei and Beijing is $6 \mathrm{kA}$. The HVDC grid and hybrid DC circuit breaker specification is summarized in Table I.

TABLE I

HYBRID HVDC CIRCUIT BREAKER SPECIFICATION

\begin{tabular}{ll}
\hline \hline \multicolumn{1}{c}{ Item } & \multicolumn{1}{c}{ Description } \\
\hline Rated power & $3000 \mathrm{MW}$ \\
Rated voltage & $\pm 500 \mathrm{kV}$ \\
Rated current & $3 \mathrm{kA}$ \\
Breaking time & $3 \mathrm{~ms}$ \\
Dielectric withstand voltage & $800 \mathrm{kV}$ \\
Maximum interrupting current & $18 \mathrm{kA}$ \\
\hline \hline
\end{tabular}

\subsection{Hybrid DC circuit breaker simulation}

The test circuit for the hybrid DC circuit breaker is simulated in Matlab/Simulink as shown in Fig. 4 [42, 43]. The test circuit consists of a $500 \mathrm{kV} \mathrm{DC}$ power supply, a DC reactor to limit the rate of rise of the fault current, a load resistor and a switch. The switch is connected in parallel with the load resistor, in order to create the fault condition. The load resistor is $166 \Omega$ so that normal operating current is $3 \mathrm{kA}$. Based on the system voltage and current rating, the current limiting DC reactor is selected to be $100 \mathrm{mH}$ to limit the maximum interrupting current to $18 \mathrm{kA}$ at $3 \mathrm{~ms}$ after fault occurs. In this case, the maximum rate of rise of the fault current is $5 \mathrm{kA} / \mathrm{ms}$.

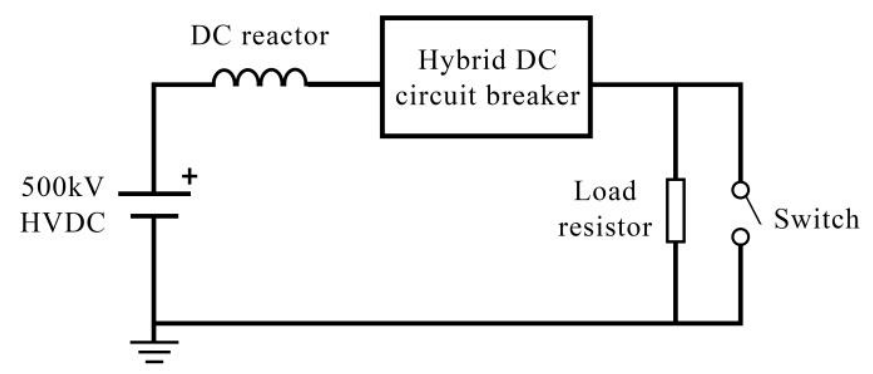

Fig. 4. Testing circuit in the Matlab/Simulink simulation.

This paper focus on comparison of the different mechanisms to commutate the current from the mechanical switch to the semiconductor switch and create a zero current for the mechanical switch. The system constraints for the mechanical switch and the semiconductor switch are assumed to be the same for comparison. The time to fully open the mechanical switch is assumed to be $2 \mathrm{~ms}[7,24]$. The ABB StakPak insulated-gate bipolar transistor (IGBT) module 
5SNA3000K452300 is selected for the semiconductor switch. The voltage rating of the IGBT is $4500 \mathrm{~V}$ and the current rating is $3000 \mathrm{~A}$. The dielectric voltage withstand of the hybrid DC circuit breaker is $800 \mathrm{kV}$ as shown in Table I. The semiconductor switch in the hybrid DC breaker therefore has 180 IGBT connected in series and 4 connected in parallel. The collector-emitter saturation voltage of the IGBT is between $2.85 \mathrm{~V}$ and $3.95 \mathrm{~V}$. A voltage drop of $3.5 \mathrm{~V}$ is assumed for each IGBT and the total voltage drop of the semiconductor switch would be $630 \mathrm{~V}$ when it is conducting the current.

In the Matlab/Simulink model, the mechanical switch is represented by a breaker block, which only opens when a low control signal is given, and the current through it reduces to zero. The contact resistance of the mechanical switch is defined as $10 \mu \Omega$ [46]. The semiconductor switch is simulated by an IGBT block with the total collector-emitter saturation voltage defined as $630 \mathrm{~V}$ to represent 180 IGBT connected in series. The coupled inductor is simulated by a mutual inductance block, where the self-inductance and mutual inductance are defined. The resistance of the winding is defined as $0.86 \mathrm{~m} \Omega$ when the self-inductance is $1 \mathrm{mH}$.

The operation of the proactive hybrid DC circuit breaker shown in Fig. 1 was simulated and the results presented in Fig. 5. Fig. 5 (a) shows the system current in the DC grid and the voltage across the hybrid DC circuit breaker. Fig. 5 (b) shows the current in the mechanical switch, semiconductor switch and varistor, respectively. During normal operation, the system current is the rated current of $3 \mathrm{kA}$ and all the current flows through the mechanical switch. The load resistor is short circuited by the switch at $1 \mathrm{~ms}$ to simulate the fault. The system current starts to increase at the rate of $5 \mathrm{kA} / \mathrm{ms}$. It is assumed that the fault is detected when the system current is $6 \mathrm{kA}$, the load commutation switch is turned off and the system current is transferred to the semiconductor switch. The semiconductor switch suffers from a high $d i / d t$ at this time instance. The mechanical switch is fully opened within $2 \mathrm{~ms}$ and the semiconductor switch is turned off at $3.6 \mathrm{~ms}$. The varistor limits the voltage across the hybrid DC circuit breaker to $800 \mathrm{kV}$. The varistor takes $7 \mathrm{~ms}$ to absorb the residual energy in the system due to the large $100 \mathrm{mH}$ DC reactor.

It should be noted that the simulation is based on the fault being detected when the fault current is higher than $6 \mathrm{kA}$. If it took more than $3 \mathrm{~ms}$ for the breaker controller to decide to initiate operation, the system current would be too high for the hybrid DC circuit breaker to interrupt unless a higher value of DC reactor were used, to reduce the rate of current rise [7, 29].


Fault detected at $6 \mathrm{kA}$, current commutation time of $100 \mu \mathrm{s}$

Fig. 5. Current and voltage of hybrid DC circuit breaker shown in Fig. 1.

The hybrid DC circuit breaker with the commutation booster shown in Fig. 2 was also simulated. The selfinductance for the primary winding and secondary winding was defined as $4 \mathrm{mH}$ and $1 \mathrm{mH}$, respectively. The coupling coefficient for the coupled inductor was assumed to be 0.95 and therefore the mutual inductance is $1.9 \mathrm{mH}$. The simulation results are shown in Fig. 6 . When the fault is applied at $1 \mathrm{~ms}$, the current in the mechanical switch transfers to the semiconductor switch due to the arrangement of the commutation booster. As shown in in Fig. 6 (b), it is clear that the mechanical switch does not experience high current during the fault. Also the rate of rise of the current in the semiconductor switch is more acceptable in this case. The current commutation time is defined as the time that the current is fully transferred from the mechanical switch to the semiconductor switch. The current in the mechanical switch reduces to zero at $1.95 \mathrm{~ms}$. The current commutation time is $0.95 \mathrm{~ms}$ for this case. The subsequent operation is similar to the proactive hybrid DC circuit breaker. In this topology, the mutual inductance has to be greater than the self-inductance of the secondary winding to transfer the current in the mechanical switch branch to the semiconductor branch. If the self-inductance of primary and secondary winding is the same, the fault current will not commutate from the mechanical switch to the semiconductor switch. 

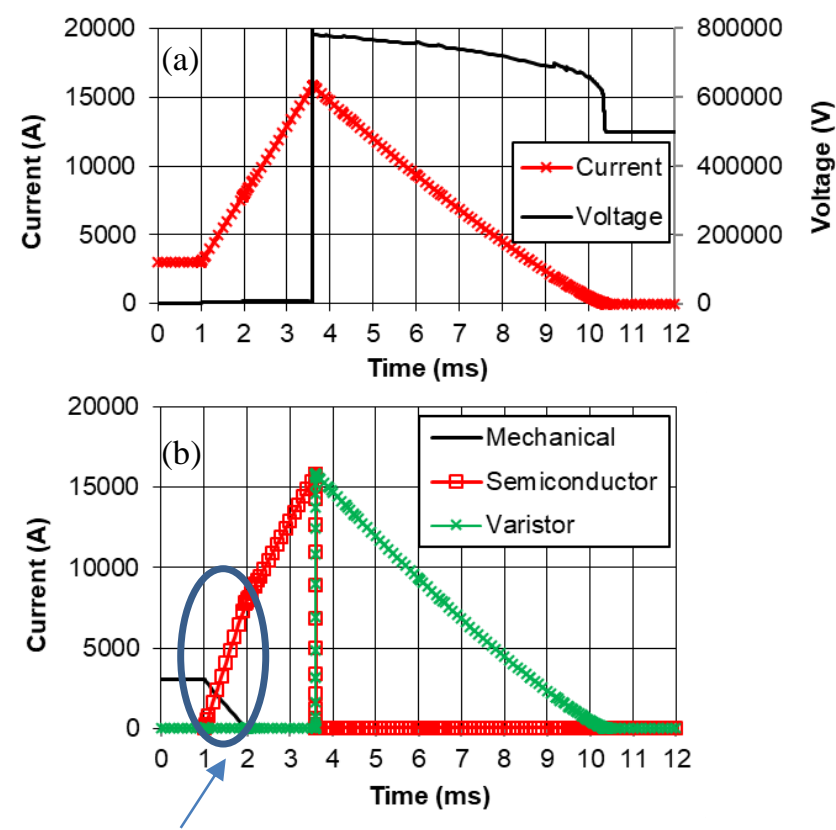

Current commutation time of $0.95 \mathrm{~ms}$

Fig. 6. Current and voltage of hybrid DC circuit breaker with commutation booster shown in Fig. 2.

The hybrid DC circuit breaker with coupled inductor shown in Fig. 3 has less constraint on the inductance values. The selfinductance of the primary and secondary winding is assumed to be $1 \mathrm{mH}$. The mutual inductance is $0.95 \mathrm{mH}$ with a coupling coefficient of 0.95 . The simulation results for the hybrid DC circuit breaker with the coupled inductor are shown in Fig. 7. The current commutation time is $0.73 \mathrm{~ms}$. Compared with the hybrid DC circuit breaker with a commutation booster, the inductance is less constrained and the current commutation time is faster. The operation and functionality of these two hybrid DC circuit breakers are similar. A detailed sensitivity study will be discussed in the next section. It should be noted that when the semiconductor switch is turned off, the voltage across the mechanical switch is $3 \mathrm{kV}$ higher than the voltage across the hybrid DC circuit breaker presented in Fig. 7. This is because the sudden change of the current in the coupled inductor leads to the induced overvoltage on the mechanical switch.
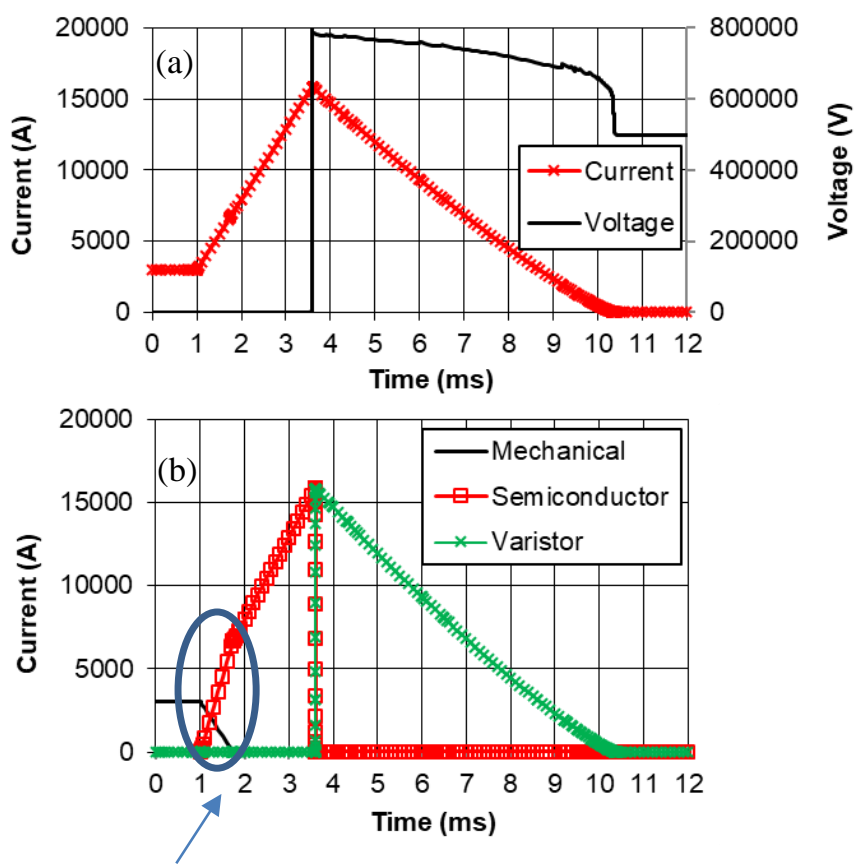

Current commutation time of $0.73 \mathrm{~ms}$

Fig. 7. Current and voltage of hybrid DC circuit breaker with coupled inductor shown in Fig. 3.

The operating losses of the proactive hybrid DC circuit breaker depend on the IGBT collector-emitter saturation voltage in the LCS. The maximum conduction IGBT losses for $2.7 \mathrm{kA}$ DC are estimated between $4.5 \mathrm{~kW}$ and $6.9 \mathrm{~kW}$ with different numbers of parallel branches [47]. The operating losses of the hybrid DC circuit breaker with coupled inductor depends on the intrinsic resistance of the copper winding. The resistance for the air-core inductor of $1 \mathrm{mH}$ is approximately $0.86 \mathrm{~m} \Omega$ under the normal operation of $2.7 \mathrm{kA}$. The operating losses of an inductor winding are $6.3 \mathrm{~kW}$ and the losses can be reduced to half if the cross-sectional area of the copper cable doubles. The operating losses of the hybrid DC circuit breakers are therefore comparable.

\subsection{Factors affect the current commutation}

This section will compare the current commutation in the hybrid DC circuit breaker with the commutation booster and the hybrid DC circuit breaker with the coupled inductor. In these two topologies, when the mechanical switch and semiconductor switch are on, the current commutation from the mechanical switch to the semiconductor switch occurs automatically during a fault condition. A sensitivity study for the current commutation time is carried out in this section. The factors that have an impact on the current commutation include the rate of rise of the fault current, the self-inductance and the coupling coefficient of the coupled inductor are all investigated.

Depending on the location and the type of the fault in the DC grid, the rate of rise of the fault current is different. The rate of rise of the fault current was $5 \mathrm{kA} / \mathrm{ms}$ in section 3.2. Rates of rise of fault current of $2 \mathrm{kA} / \mathrm{ms}, 3 \mathrm{kA} / \mathrm{ms}, 4 \mathrm{kA} / \mathrm{ms}$ and $5 \mathrm{kA} / \mathrm{ms}$ were considered here and are summarized in Fig. 8. This shows that the faster the fault current rises in the system, the faster the current commutation from the 
mechanical switch branch to the semiconductor switch branch. The current commutation in the hybrid DC circuit breaker with coupled inductor is consistently faster than the hybrid DC circuit breaker with commutation booster. It should be noted that the coupled inductor needs to be designed to be able to create current zero-crossing for the mechanical switch under different fault conditions, in particular for the high impedance fault when the rate of rise of the fault current is slow.

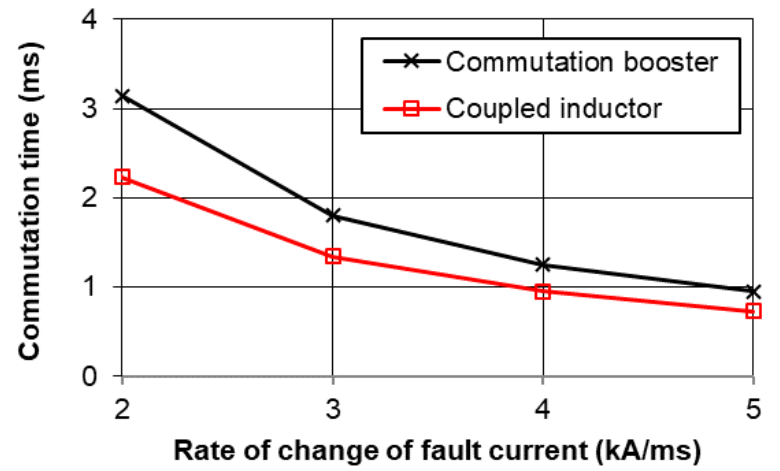

Fig. 8. Impact of rate of change of fault current on commutation time.

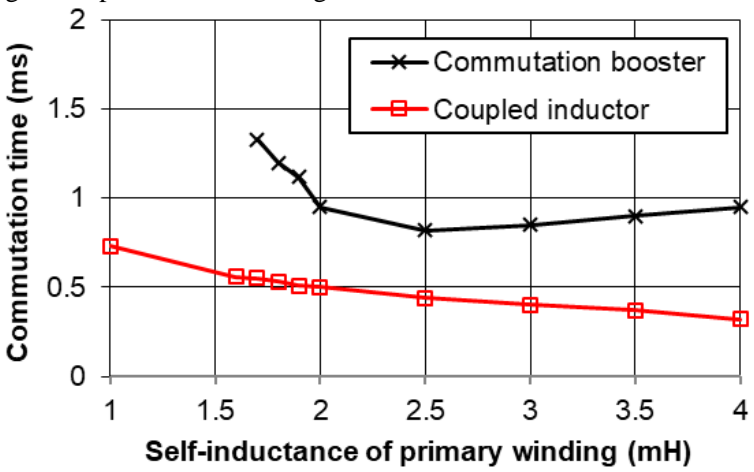

Fig. 9. Impact of self-inductance of primary winding on commutation time.

The self-inductance of the primary winding of the coupled inductor is varied to understand design limitations. The selfinductance of the secondary winding is assumed to be $1 \mathrm{mH}$ and the coupling coefficient of the coupled inductor is assumed to be 0.95 . Fig. 9 presents the impact of the selfinductance of the primary winding on the current commutation time. Again the current commutation in the hybrid DC circuit breaker with coupled inductor is consistently faster than the hybrid DC circuit breaker with the commutation booster. The current commutation time for the hybrid DC circuit breaker with the commutation booster increases as the self-inductance of primary winding reduces from $2.5 \mathrm{mH}$. When the selfinductance of the primary winding is less than $1.6 \mathrm{mH}$, however, the current is not able to commutate from the mechanical switch to the semiconductor switch. The current commutation time for the hybrid DC circuit breaker with coupled inductor only changes slightly with the change of selfinductance of primary winding. This confirms that the hybrid DC circuit breaker enables greater flexibility in the design and selection of the self-inductance of the coupled inductor.

The coupling coefficient of the coupled inductor is determined by the layout of the primary and secondary windings. The effect of the coupling coefficient of the coupled inductor on the current commutation was also investigated and presented in Fig. 10. The coupling coefficient of the coupled inductor is varied from 0.7 to unity. The current commutation time only increases slightly for the hybrid DC circuit breaker with the coupled inductor when the coupling coefficient reduces. However, the current commutation time for the hybrid DC circuit breaker with the commutation booster increases significantly when the coupling coefficient reduces.



Fig. 10. Impact of coupling coefficient of coupled inductor on commutation time.

From the above comparison, it is evident that the hybrid DC circuit breaker with the coupled inductor has three advantages compared to the hybrid DC circuit breaker with the commutation booster: firstly, the current commutation is faster under the same conditions; secondly, the selection and design of the coupled inductor is more flexible; and thirdly, the operation is less sensitive to the coupling of the coupled inductor.

The hybrid DC circuit breaker can interrupt fault current with different rates of rise of the fault current. A low voltage rating semiconductor device can be added in series with the mechanical circuit breaker for current commutation to interrupt rated currents and overload currents.

\section{Laboratory prototype design and experimental results}

\subsection{Test circuit and prototype DC circuit breaker}

A prototype hybrid DC circuit breaker with coupled inductor was designed and tested to confirm its operation and support the above analysis. Fig. 11 presents the testing circuit for the prototype hybrid DC circuit breaker. The testing circuit consists the following devices: a programmable DC power supply up to $50 \mathrm{~V} / 400 \mathrm{~A}$, a high current rating diode, a load resistor, a switch, and a prototype DC circuit breaker under test. A DC power supply was used to generate the current during normal operation and short-circuit fault condition. The diode was connected in series with the DC power supply to block any reverse voltage created by inductance during fault current interruption and protect the DC power supply.

Fig. 12 shows the prototype hybrid DC circuit breaker with coupled inductor, which consists of a coupled inductor, a vacuum circuit breaker (mechanical switch) and an IGBT (semiconductor switch). The operation sequence of the vacuum circuit breaker and the IGBT was set by a microcontroller. Two coaxial coils were wound onto a round wooden cable reel to form the coupled inductor. Copper cable was used to build the coupled inductor. The diameter of the wooden cable reel was $200 \mathrm{~mm}$ and the height was $150 \mathrm{~mm}$. 
The value of inductance was chosen to have a current commutation time of $2 \mathrm{~ms}$. The coupled inductor was designed using a finite element (FE) electromagnetic software package. The layout of the coupled coaxial windings using an axisymmetric finite element model is shown in Fig. 13. The primary winding was made of 51 turns and the self-inductance was found from the model to be $453 \mu \mathrm{H}$. The secondary winding was made up of 24 turns and the self-inductance was $158 \mu \mathrm{H}$. The mutual inductance between the primary winding and the secondary winding was $174 \mu \mathrm{H}$. The measured inductances were within $5 \%$ of the FE model estimation. The coupling coefficient in this case was 0.65 . This could be increased by, for example, interleaving the coils if necessary.

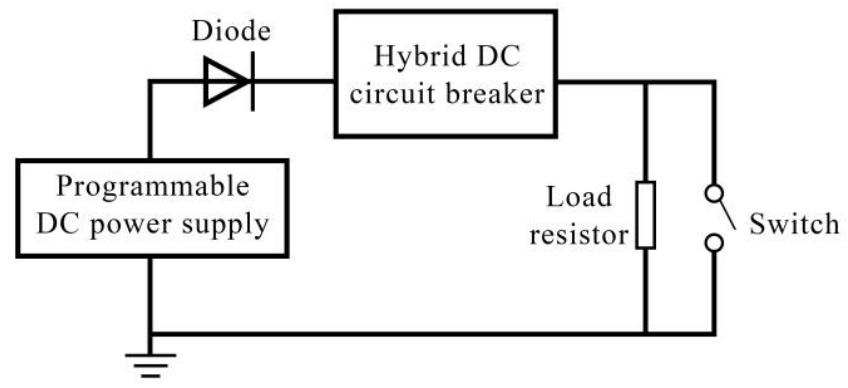

Fig. 11. Testing circuit schematic.

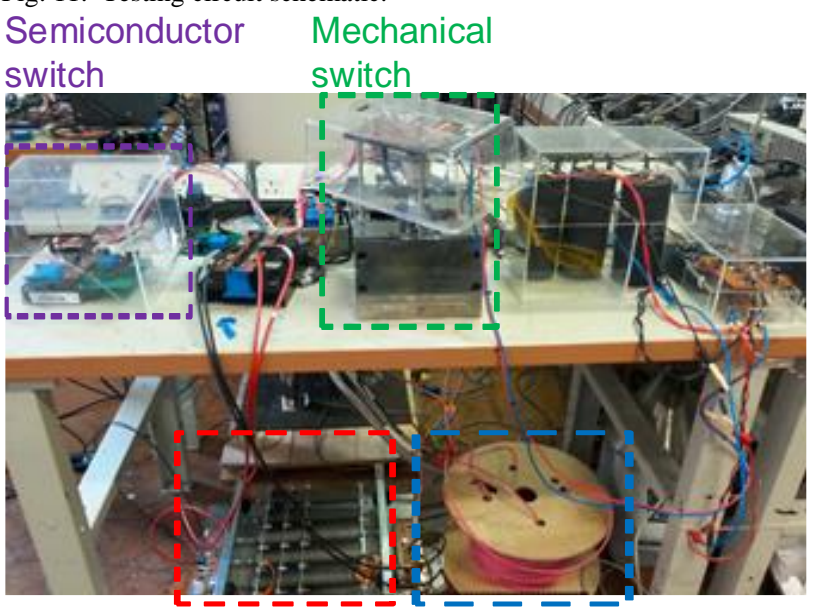

Load resistor Coupled inductor

Fig. 12. Hybrid DC circuit breaker with series connected coupled inductor prototype.

The mechanical switch in the protytype used a vacuum circuit breaker. The vacuum circuit breaker was rated at $320 \mathrm{~A}$. The stroke of the vacuum circuit breaker was $2 \mathrm{~mm}$ with the maximum operating voltage of $1.5 \mathrm{kV}$. The vacuum circuit breaker was operated by a light-weight moving copper coil, neodymium magnets $(\mathrm{NdFeB})$ and an electrical steel magnetic circuit actuator to achieve high speed operation [48].

The semiconductor switch branch used an IGBT with a current rating of $2.5 \mathrm{kA}$ and a voltage rating of $1.7 \mathrm{kV}$ during normal operation. A resistor-capacitor-diode (RCD) snubber circuit was used to limit the rate of rise of the voltage across the IGBT after current interruption. A metal oxide varistor (MOV) B40K75 with a maximum DC operating voltage of $100 \mathrm{~V}$ was also connected in parallel with the IGBT. The voltage across the DC circuit breaker prototype after current interruption was limited by the varistor.

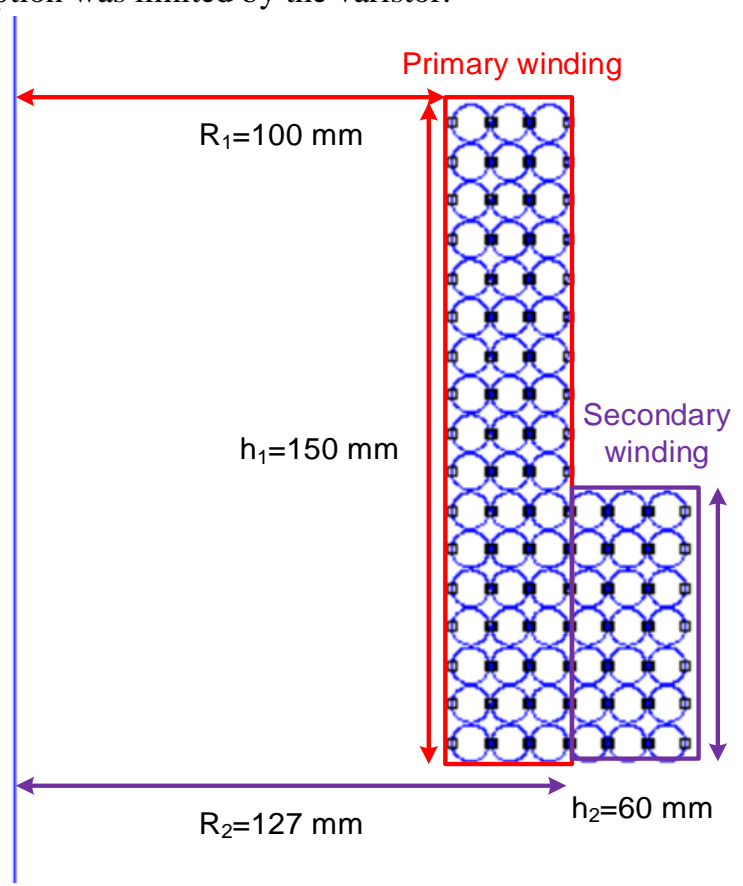

Fig. 13. Coupled inductor winding layout using axisymmetric model.

\subsection{Experimental results}

Fig. 14 presents the experimental testing results for the prototype hybrid DC circuit breaker with coupled inductor. The waveforms in Fig. 14 are the total system current, the current in the vacuum circuit breaker, the current in the IGBT and varistor, and voltage across the hybrid DC circuit breaker, respectively.

Initially the prototype hybrid DC circuit breaker was subjected to a normal operation current of $75 \mathrm{~A}\left(\mathrm{t}_{0}\right)$. The vacuum circuit breaker and the IGBT are kept on. The current flowed through the vacuum circuit breaker due to its low resistance conduction path during normal operation.

The load resistor was then short-circuited by the switch and a fault was created at $\mathrm{t}_{1}=3 \mathrm{~ms}$. When the fault was applied, the current in the testing circuit started to rise. The increasing current in the primary winding induced a back emf across the secondary winding. This emf forces the current to start to transfer from the vacuum circuit breaker to the IGBT as shown in Fig. 6 (b) and (c). During the short-circuit fault, the current in the vacuum circuit breaker shown in Fig. 6 (b) naturally reduced when the fault current increases. The fault current automatically commutated into the IGBT as shown in Fig. 6 (c).

The design creates an artificial zero current for the vacuum circuit breaker at $t_{2}=5 \mathrm{~ms}$. The current commutation time was deliberately designed for $2 \mathrm{~ms}$ because it took $2 \mathrm{~ms}$ for actuator to accelerate before the contacts of the vacuum circuit breaker started to open. The vacuum circuit breaker was fully open within $1.5 \mathrm{~ms}$.

At $t_{3}=6.6 \mathrm{~ms}$, the IGBT was turned off when the vacuum circuit breaker was fully open and recovered to the voltage withstand capability. The voltage across the IGBT, which was also the voltage across the prototype DC circuit breaker, increases quickly, though this rate was initially limited by the 
RCD snubber circuit. When the voltage across the prototype DC circuit breaker was higher than the maximum DC operating voltage of $100 \mathrm{~V}$, the varistor started to conduct. The hybrid DC circuit breaker voltage was limited to under $180 \mathrm{~V}$ when the current through the varistor was $200 \mathrm{~A}$, which matched the voltage-current characteristics of B40K75 varistor. The varistor absorbed the residual energy in the test circuit.

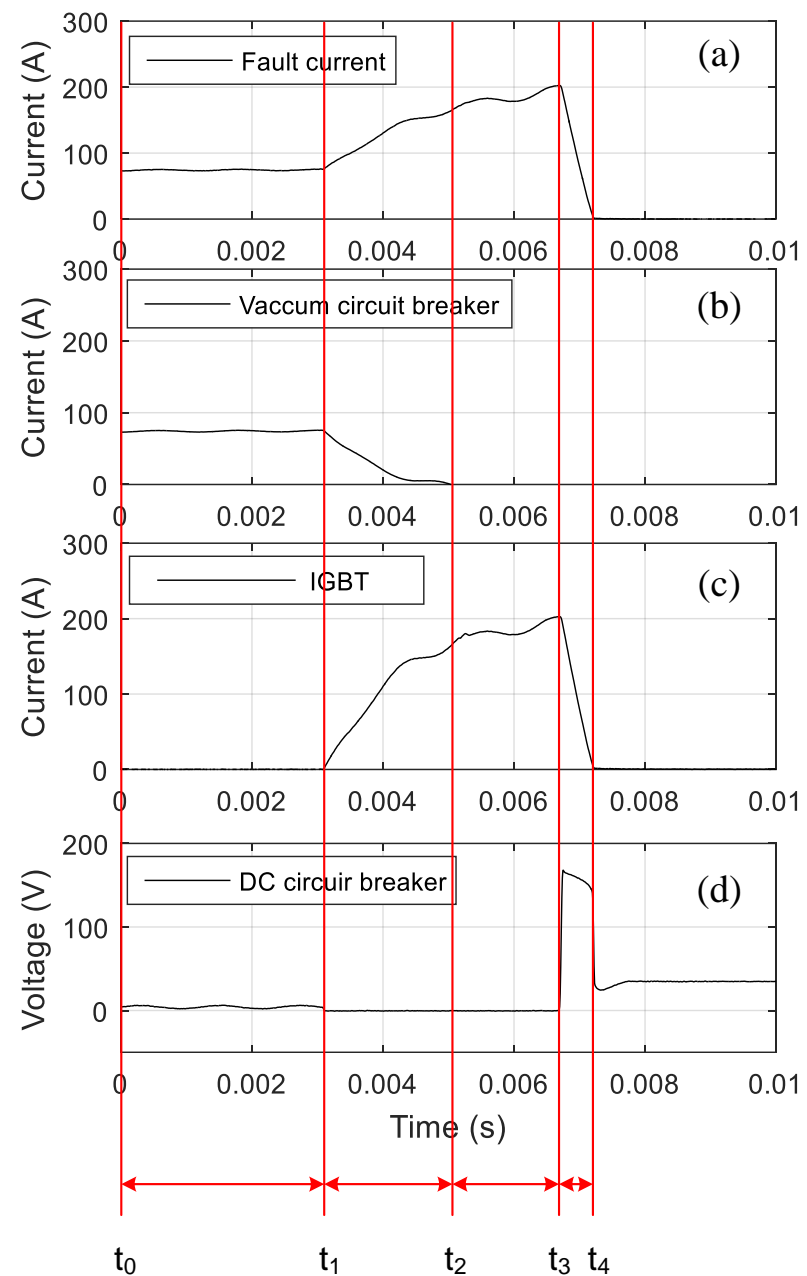

Fig. 14. Hybrid DC circuit breaker with series connected coupled inductor experimental results.

At $t_{4}=7 \mathrm{~ms}$, the current in the system reduced to zero, which means the varistor fully absorbed and dissipated the residual energy. The prototype hybrid DC circuit breaker therefore interrupted DC current of 200 A within $4 \mathrm{~ms}$ successfully from when the fault started $(3 \mathrm{~ms})$. The current interruption time could be further reduced when a fast-acting vacuum circuit breaker and its actuator have been developed. The voltage and current level of the hybrid DC circuit breaker can also be scaled up by series and/or parallel connection of the vacuum circuit breakers, IGBTs and varistors.

\section{Conclusion}

This work proposes a new hybrid DC circuit breaker which utilizes a coupled inductor connected in series to assist current commutation once a fault occurs. The operation of three hybrid DC circuit breakers is analyzed and compared. The hybrid DC circuit breaker with commutation booster and the hybrid DC circuit breaker with coupled inductor offers automatic current commutation once a fault occurs. The hybrid DC circuit breaker with coupled inductor proposed in this paper has faster current commutation than the hybrid DC circuit breaker with commutation booster under the same conditions. Also the hybrid DC circuit breaker with coupled inductor has less constraints in designing the coupled inductor.

A low current technology demonstrator was designed and tested successfully. The proposed hybrid DC circuit breaker prototype has demonstrated successful interruption of $200 \mathrm{~A}$ DC current within $4 \mathrm{~ms}$. A fully optimized hybrid DC circuit breaker using a fast vacuum circuit breaker can potentially reduce the breaking time to below $3 \mathrm{~ms}$. The advantages of the proposed coupled-inductor hybrid DC circuit breaker include:

- Automatic and fast current commutation by mutual inductance. Once a fault occurs, the current in the mechanical switch is quickly forced into the semiconductor switch automatically. The mechanical switch can be opened with the current reduces close to zero.

- The current commutation is faster when the rate of rise of the fault current is higher.

\section{Acknowledgements}

This work was funded as part of the UK EPSRC, FCL/CB: An Integrated VSC-HVDC Fault Current Limiter/Breaker project, EP/L021552/1.

\section{References}

[1] N. Flourentzou, V. G. Agelidis, and G. D. Demetriades, VSC-based HVDC power transmission systems: an overview, IEEE Trans. Power Electron 2009; 24(3), 592-602.

[2] M. Barnes, and A. Beddard, Voltage source converter HVDC links - The state of the art and issues going forward, Energy Procedia 2012; 24, 108122.

[3] W. Ling, W. Sun, and J. Zhang, Analysis of typical operating modes of Zhoushan multi-terminal VSC-HVDC pilot project, Power System Technology 2016; 40, (6), 1751-1758.

[4] H. Rao, Architecture of Nan'ao multi-terminal VSC-HVDC system and its multi-functional control, CSEE Journal of Power and Energy Systems 2015; 1(1), 9-18.

[5] G. Tang, Z. He, H. Pang, X. Huang, and X. Zhang, "Basic topology and key devices of the five-terminal DC grid, CSEE Journal of Power and Energy Systems 2015; 1(2), 22-35.

[6] B. Tian, X. Mo, Y. Shen, W. Lei, and P. Xu, Prospect and key techniques of global energy interconnection Zhangjiakou innovation demonstration zone, Global Energy Interconnection 2018, 1 (2), 153161.

[7] G. Tang, H. Pan, Z. He, and X. Wei, Research on key technology and equipment for Zhangbei 500kV DC grid, High Voltage Engineering 2018; 44 (7), 2097-2106.

[8] N. Doerry and J. Amy Jr., DC voltage interface standards for naval applications, IEEE Electric Ship Technologies Symp., Old Town Alexandria, Jun. 2015.

[9] P. Gemin et al., Architecture, voltage and components for a turboelectric distributed propulsion electric grid (AVC-TeDP), NASA/CR-2015218713, 2015

[10] F. Mura, and Rik. W. De Doncker, Design aspects of a medium-voltage direct current (MVDC) grid for a university campus, 8th Int. Conf. on Power Electronics - ECCE Asia, 2011.

[11] F. Mura, and Rik. W. De Doncker, Preparation of a medium-voltage DC grid demonstration project, E.ON Energy Research Center Series 2012; 4(1), 1-32.

[12] N. A. Belda, C. Plet, C. Spallarosa, and K. Tahata, PROMOTioN D5.1: HVDC network fault analysis, Oct. 2016. [Online]. Available: https://www.promotion- 
offshore.net/news_events/news/detail/deliverable-51-hvdc-networkfault-analysis/.

[13] N. A. Belda, C. Plet, C. Spallarosa, and K. Tahata, PROMOTioN D5.3: Fault stress analysis of HVDC circuit breakers, Jan. 2017. [Online]. Available: https://www.promotionoffshore.net/news_events/news/detail/deliverable-53-fault-stressanalysis-of-hvdc-circuit-breakers/.

[14] O. Cwikowski, A. Wood, A. Miller, M. Barnes, and R. Shuttleworth, Operating DC circuit breakers with MMC, IEEE Tran. Power Del 2018; 33(1), 260-270.

[15] O. Cwikowski, H. R. Wickramasinghe, G. Konstantinou, J. Pou, M. Barnes, and R. Shuttleworth, Modular multilevel converter DC fault protection, IEEE Tran. Power Del 2018; 33(1), 291-300.

[16] X. Pei, O. Cwikowski, D. S. Vilchis-Rodriguez, M. Barnes, A. C. Smith, and R. Shuttleworth, A review of technologies for MVDC circuit breakers, 42nd Annual Conf. of the IEEE Industrial Electronics Society (IECON), Florence, 2016; 3799-3805.

[17] B. Pauli, G. Mauthe, E. Ruoss, G. Ecklin, J. Porter, and J. Vithayathil, Development of a high current HVDC circuit breaker with fast fault clearing capability, IEEE Tran. Power Del 1988; 3(4), 2072-2080.

[18] ABB circuit-breakers for direct current applications, ABB SACE S.p.A., 2007.

[19] S. Liu, and M. Popov, Development of HVDC system-level mechanical circuit breaker model, Int J Elec Power 2018; 103, 159-167.

[20] S. Liu, M. Popov, S.S. Mirhosseini, S. Nee, T. Modeer, L. Ängquist, N. Belda, K. Koreman, and M. van der Meijden, Modelling, experimental validation and application of VARC HVDC circuit breakers, IEEE Tran. Power Del 2019 (Early Access).

[21] C. Meyer, M. Kowal, and R. W. De Doncker, Circuit breakers concepts for future high-power DC-applications, Proc. 40th IEEE IAS Annu. Meeting Conf 2005; 860-866.

[22] D. Jovcic, and B. Wu, Fast fault current interruption on high-power DC networks, IEEE Power and Energy Society General Meeting, 2010.

[23] J. Häfner and B. Jacobson, Proactive hybrid HVDC breakers - A key innovation for reliable HVDC grids, integrating supergrids and microgrids, Proc. CIGRE Symp., Bologna, Italy, 2011.

[24] M. Callavik, and A. Blomberg, The hybrid HVDC breaker, ABB Grid Systems, 2012.

[25] W. Grieshaber, J. P. Dupraz, D. L. Penache, and L. Violleau, Development and test of a $120 \mathrm{kV}$ direct current circuit breaker, Proc. CIGRE, Paris, France, 2014.

[26] W. Zhou, X. Wei, S. Zhang, G. Tang, Z. He, J. Zheng, Y. Dan and C. Gao, Development and test of a 200kV full-bridge based hybrid HVDC breaker, 17th European Conference on Power Electronics and Applications (EPE'15 ECCE-Europe), Geneva, Switzerland, 2015.

[27] A. Shukla, and G. D. Demetriades, A survey on hybrid circuit-breaker topologies, IEEE Trans. Power Del 2015; 30(2), 627-641.

[28] J. Zhou et al., Research of DC circuit breaker applied on Zhoushan multi-terminal VSC-HVDC project, IEEE PES Asia-Pacific Power and Energy Eng. Con. (APPEEC), Xi'an, 2016; 1636-1640.

[29] X. Pei, G. Tang, and S. Zhang, Sequential auto-reclosing strategy for hybrid HVDC breakers in VSC-based DC grids, J. Mod. Power Syst. Clean Energy 2019; 7(3), 633-643.

[30] C. Zhuang, X. Bing, Y. Zhanqing and W. Nianhua, Research on topological structure and simulation of hybrid DC circuit breaker, The Journal of Engineering 2019; 16, 3310-3314.

[31] C. Gao, X. Ding, G. Tang, G. Wang, P. Qiu, Key stress extraction and equivalent test method for hybrid DC circuit breaker, Global Energy Interconnection 2018; 1(1), 29-38.

[32] O. Cwikowski, M. Barnes, R. Shuttleworth, and B. Chang, Analysis and simulation of the proactive hybrid circuit breaker, 11th IEEE Int. Conf. on Power Electronics and Drive Systems, Sydney, 2015.

[33] J. Martinez-Velasco, J. Magnusson, Parametric analysis of the hybrid HVDC circuit breaker, Int J Elec Power 2017; 84, 284-295.

[34] W. Wang, M. Barnes, O. Marjanovic, and O. Cwikowski, Impact of DC breaker systems on multiterminal VSC-HVDC stability, IEEE Trans, Power Del 2016; 31(2), 769-779.

[35] W. Wen, Y. Huang, Y. Sun, J. Wu, M. Al-Dweikat, and W. Liu, Research on current commutation measures for hybrid DC circuit breakers, IEEE Tran. Power Del 2016; 31(4), 1456-1463.

[36] C. M. Franck, HVDC circuit breakers: A review identifying future research needs, IEEE Tran. Power Del 2011; 26(2), 998-1007.

[37] M. Chen, Y. Yamada, S. Zen, and K. Yasuoka, Study on molten bridge behaviors with arc-less current commutation in a hybrid DC circuit breaker, IEEE Holm Conference on Electrical Contacts 2017; 34-39.
[38] C. Peng, A. Q. Huang, and X. Song, Current commutation in a medium voltage hybrid DC circuit breaker using $15 \mathrm{kV}$ vacuum switch and $\mathrm{SiC}$ devices, IEEE Applied Power Electronics Conference and Exposition (APEC) 2015; 2244-2250.

[39] J. Magnusson, L. Liljestrand, and R. Saers, Apparatus arranged to break an electrical current, Patent WO2014032692, 2014.

[40] J. Magnusson, R. Saers, and L. Liljestrand, The commutation booster, a new concept to aid commutation in hybrid DC-breakers, CIGRE, Lund, 2015.

[41] K. A. Corzine, A new-coupled-inductor circuit breaker for DC applications," IEEE Trans. Power Electron 2017; 32(2), 1411-1418.

[42] A. Mokhberdoran, A. Carvalho, N. Silva, H. Leite, and A. Carrapatoso, A new topology of fast solid-state HVDC circuit breaker for offshore wind integration applications, Proc. 17th Eur. Conf. Power Electron. Appl 2015; 1-10.

[43] A. Ray, K. Rajashekara, S. N. Banavath, and S. K. Pramanick, Coupled inductor-based zero current switching hybrid DC circuit breaker topologies, IEEE Trans. Ind. Appl. 2019; 55(5), 5360-5370.

[44] N. A. Belda, and R. P. P. Smeets, Test circuits for HVDC circuit breakers, IEEE Trans. Power Del 2017; 32(1), 285-293.

[45] O. Cwikowski, B. Chang, and M. Barnes, Fault current testing envelopes for VSC HVDC circuit breakers, IET Gener. Transm. Distrib 2016; 10(6), 1393-1400.

[46] E. Dullni, D. Gentsch, W. Shang, and T. Delachaux, Resistance increase of vacuum interrupters due to high-current interruptions, IEEE Trans. Dielectr. Electr. Insul 2016; 23(1), 1-7.

[47] A. Hassanpoor, J. Hafner, and B. Jacobson, Technical assessment of load commutation switch in hybrid HVDC breaker, IEEE Trans. Power Electron 2015; 30(10), 5393-5400.

[48] X. Pei, A. C. Smith, R. Shuttleworth, D. S. Vilchis-Rodriguez, and M. Barnes, Fast operating moving coil actuator for a vacuum circuit breaker, IEEE Trans. Energy Convers 2017; 32(3), 931-940. 